\title{
Mediating role of childhood abuse for the relationship between schizotypal traits and obsessive-compulsive disorder
}

\author{
Cagdas OyKu Memis \\ https://orcid.org/0000-0001-6777-4172 \\ Bilge Dogan ${ }^{1}$ \\ https://orcid.org/0000-0001-7895-9738 \\ Doga SEVINCOK² \\ https://orcid.org/0000-0003-3138-6922 \\ ISMET ASHIK ${ }^{2}$ \\ https://orcid.org/0000-0002-5331-5570 \\ LEVENT SEVINCOK ${ }^{1}$ \\ https://orcid.org/0000-0003-3770-8881
}

1 Department of Psychiatry, Adnan Menderes University, Aydin, Turkey.

2 Department of Child and Adolescent Psychiatry, Adnan Menderes University, Aydin, Turkey.

Received: 03/16/2019 - Accepted: 11/05/2019

DOl: 10.1590/0101-60830000000229

\begin{abstract}
Background: The mediating role of childhood trauma in the relationship between schizotypal symptoms and obsessive-compulsive disorder (OCD) was not sufficiently investigated to date. Objectives: In the present study, our major goal was to analyse the mediator role of childhood abuse (emotional, physical, and sexual), and neglect (emotional and physical) on the link between schizotypal symptoms and OCD, after controlling for duration of OCD, the mean number of comorbid Axis I disorders, and current anxiety. Methods: One hundred fifteen patients (aged 18-65 years) who had primary diagnosis of OCD and YaleBrown Obsessive-Compulsive Scale score $\geq 16$ were assessed using the short form of Childhood Trauma Questionnaire questionnaire (CTQ-SF), Schizotypal Personality Questionnaire (SPQ), and Beck Anxiety Inventory (BAI). Results: The all types of schizotypal symptoms were significantly correlated with the scores of childhood abuse and neglect, and BAI. The childhood abuse as a mediator significantly predicted the total YBOCS scores $(\mathrm{p}=0.02)$ after when BAI scores were controlled. However, childhood neglect was not multivariately related to current OCD severity, and did not mediate the relationship between schizotypal traits and total YBOCS scores. Discussion: We suggested that childhood trauma mediated the schizotypal traits in relationship with current OCD severity independent from anxiety severity.
\end{abstract}

Memis CO et al. / Arch Clin Psychiatry. 2020;47(2):40-4

Keywords: Obsessive-compulsive disorder, childhood trauma, schizotypal traits.

The obsessive-compulsive disorder (OCD) is a psychiatric disorder characterized by obsessions and/or compulsions, which affects $1 \%-3 \%$ of the population through the world ${ }^{1}$. There is growing evidence of differences in demographic and clinical characteristics of OCD patients with and without schizotypal traits, indicating a schizotypal subgroup of $\mathrm{OCD}^{2-8}$. Schizotypal traits emerged as a potent predictor of OCD symptoms relative to depression or general anxiety $2,4,9$. The term "schizotypal" describes psychopathological characteristics that are chronic, and stable over time and are assumed to represent an inherited general vulnerability to psychopathology that falls between healthy conditions and severe mental illness9,10. Cognitive-perceptual (positive), interpersonal (negative), and disorganization factors were described as prominent schizotypal traits ${ }^{11}$. Several studies demonstrated a link between positive symptoms of schizotypy (magical thinking, unusual perceptual experiences, ideas of reference, paranoid ideations) and OCS ${ }^{6,8,12}$. These patients with OCD and positive symptoms of schizotypy have been found to have more severe OCD symptoms ${ }^{12-14}$, more prominent obsessions ${ }^{14,15}$, a poorer prognosis ${ }^{13}$ and an earlier age of onset of their disorder ${ }^{2,16}$. OCD and high-schizotypy has also been associated with specific OCD symptoms such as checking, counting, ordering/arranging, and hoarding 2,3,5. Autogenous type of obsessions were suggested to be more highly associated with schizotypal features such as magical thinking, and anomalous perceptions ${ }^{4}$. However, little is known about how schizotypal traits contribute to OCD symptoms. One explanation is that the magical thinking of schizotypy may increase the risk for displaying the cognitive bias of likelihood thought-action fusion (TAF), which in turn may increase the risk for $\mathrm{OCD}^{4}$. Schizotypy traits may be linked to OCD symptoms through multiple pathways. In the present study, we supposed that childhood trauma may serve as a mediator on the link between schizotypal traits and OCD. In fact, childhood trauma may cause and contribute to the presence of personality disorders and emotional and behavioural deficits ${ }^{17}$. Some cross-sectional, prospective, and retrospective studies suggested an association between childhood trauma and increased schizotypal traits 18-20, which could not be accounted for genetic vulnerability alone ${ }^{20,21}$. Emotional abuse, neglect, and stressful childhood events were reported to be strong predictors of schizotypy 22,23 , and may result in structural and functional brain differences that leads to schizotypal symptoms ${ }^{24}$. In general, traumatic experiences during childhood have been much more linked to reality distortion than to negative and disorganized traits $25-27$. A study reported that emotional abuse alone predicted the ideas of reference, excessive social anxiety, a lack of close friends, unusual perceptual experiences and eccentric behaviour or appearance ${ }^{28}$. 
Childhood trauma is known to predispose to several mood, anxiety, and personality disorders. Childhood traumatic experiences have also been proposed to play a role in causing or precipitating OCD through some specific personality traits. In OCD patients, neuroticism, extraversion, conscientiousness and agreeableness were reported to be related to childhood abuse, while openess was not $^{29,30}$. However, the mediating role of childhood trauma in the relationship between schizotypal symptoms in OCD patients was not sufficiently investigated to date. Given the paucity of literature in this topic, we conducted a study to analyse the mediator role of childhood abuse (emotional, physical, and sexual), and neglect (emotional and physical) on the link between schizotypal symptoms and OCD. We hypothesized that if childhood trauma is related to schizotypal traits, then even would mediate their relationship with OCD even after controlling for duration of OCD, the mean number of comorbid Axis I disorders, and current anxiety.

\section{Materials and methods}

\section{Subjects and assessment}

A total of one hundred sixty patients (aged 18-65 years) who were OCD-diagnosed according to Structured Clinical Interviews for Diagnostic and Statistical Manual of Mental Disorders, Fourth Edition (DSM-IV) Axis I Disorders (SCID-I) ${ }^{31}$ at the psychiatry department between June 2016 and December 2018 were included in the study. The severity of OCD symptoms were assessed using Yale Brown Obsessive-Compulsive Scale (Y-BOCS) ${ }^{32,33}$. The subjects with total scores $\geq 16$ were required for study entry $(n=115)$. Patients with current and lifetime diagnoes of mental retardation, bipolar disorder, psychotic disorders, substance use disorders, and organic mental disorders were not included in this study. Institutional ethics committee approval was obtained prior to the study and all participants provided signed informed consent. The sociodemographic and clinical characteristics of participants, including age, sex, educational level, marital status, comorbid diagnoses of Axis I disorder, current severity of anxiety, and duration of OCD were recorded through a semi-structured interview form. The duration of OCD was determined from the age that the patient, or a family member, remembered as the beginning of the OC symptoms as used in previous studies ${ }^{34}$.

To assess experienced maltreatment in childhood and adolescence, we used the short form of Childhood Trauma Questionnaire questionnaire (CTQ-SF) in which the 28 items are rated on a 5-point Likert scale35,36. This scale includes the subscales of emotional abuse, physical abuse, sexual abuse, emotional neglect and physical neglect. For the statistical analysis, we summed the first three subscale scores into a variable "childhood abuse". We obtained the variable "childhood neglect" by summing up emotional and physical neglect scores.

Schizotypal Personality Questionnaire (SPQ) was used to assess the severity of schizotypal traits ${ }^{11,37}$. This scale was designed to have one subscale for each of the nine symptoms of schizotypal personality disorder (ideas of reference, excessive social anxiety, odd beliefs and magical thinking, unusual perceptual experiences, odd or eccentric behaviour, no close friends, odd speech, constricted affect, suspiciousness). Items were rated for agreement on a dichotomous scale (Yes/No), with a subscale score computed as the total of all items. Cognitive-perceptual/positive (magical thinking, unusual perceptual experiences, ideas of reference, paranoid ideations), interpersonal/negative (lack of close friends, constricted affect), and disorganized (odd/eccentric behavior, odd speech) dimensions were used in this study.

The severity of current anxiety was measured by Beck Anxiety Inventory (BAI) ${ }^{38}$. The BAI is a 21 -item self-report questionnaire designed specifically to distinguish symptoms of anxiety from those of depression over the past week. Each item is scored on a 4-point Likert scale, yielding a total score ranging from 0 to 63 .

\section{Statistical analysis}

All analyses were conducted using the SPSS (SPSS Science, Chicago, IL, USA) software, version 21.0. Descriptive analyses on sociodemographic, and clinical factors were conducted in terms of total number of subjects and percentage of sample. Bivariate correlations were used to determine the presence of significant associations between the schizotypal traits and several clinical variables.

The next step in our analysis was related to examine the role of childhood trauma as a mediator between schizotypal traits and the current OCD severity. The mediator is the factor through which a predictor impacts an outcome variable. To prove mediation, we followed a procedure described by Baron and Kenny ${ }^{39}$. We performed three regression equations for both childhood abuse and neglect in predicting their mediations on the relatinship between schizotypal traits and current YBOCS scores. According to this model, (a) the independent variable (schizotypal traits) should impact the mediator variable (childhood trauma) in the first equation (path a). (b) The independent variable should impact the dependent variable (YBOCS scores) in the second equation (path c). (c) The mediator should impact the dependent variable in the third equation (path b). (d) The effect of the independent variable on the dependent variable must be less in the third equation than in the second (path c'). Perfect mediation is revealed only if the independent variable has no effect when the mediator is added to the model. The mediator variable, then, serves to mediate the relationship between the independent and dependent variables. Otherwise, it is a partial mediation.

\section{Results}

\section{Sample characteristics}

Statistical analysis was executed on the basis of the data of the 115 subjects, $78(67.8 \%)$ of which were women. The mean age was $31.8(\mathrm{SD}=10.3$, range $=18-65)$ years. Fourty-nine of our participants $(42.6 \%)$ had at least one current Axis I comorbidity. The mean number of current Axis I diagnoses was $0.52 \pm 0.65$. Axis I comorbidity included the following current diagnoses: major depression $(n=30 ; 26.8 \%)$, generalized anxiety disorder $(n=8$; $6.9 \%)$, panic disorder $(n=4 ; 3.4 \%)$, Tourette Disorder $(n=3 ; 2.6 \%)$, OCD spectrum disorders $(n=4 ; 3.4 \%)$. The mean age at onset of OCD symptoms was 20.3 years old (SD:6.9, range: 5-40). The mean YBOCS scores of the participants were $33.45 \pm 4.47$ (Table 1).

\section{Correlation analysis}

As can be seen in Table 2, the all types of schizotypal symptoms were significantly correlated with the scores of childhood abuse and neglect, and BAI. There were no significant correlations between the schizotypal symptoms and the duration of OCD. Interpersonal subtype was not found to be correlated with total YBOCS scores.

\section{Mediated models for childhood abuse and neglect}

We did not insert gender, and educational level into analyses, since they were categorical, or not normally distributed. The linear regression analyses showed that total SPQ scores had an unique effect on the childhood abuse $(B=0.405,95 \%$ CI [0.243-0.565], $\beta=0.428$, $t=4.963, p<0.0001)$. Total SPQ scores were significantly associated with total YBOCS scores $(B=0.084,95 \%$ CI [0.016-0.152], $\beta=0.224, t=2.438, p=0.016)$. A hierarchical regression analyses using total YBOCS scores as the outcome variable was performed using the scores of SPQ, childhood abuse, and BAI as predictors. After including childhood abuse, direct effect of schizotypal traits on OCD severity turned out to be nonsignificant $(B=0.023,95 \%$ CI $[-0.065-0.110], \beta=0.060, t=0.513, p=0.60$ ). BAI score was not a significant predictor in the model. The childhood abuse as a mediator significantly predicted the total YBOCS scores $(B=0.093$, 
Table 1. Demographic and clinical characteristics of the participants $(n=115)$

\begin{tabular}{|l|c|c|}
\hline \multirow{2}{*}{ Variables } & \multicolumn{2}{|c|}{ Participitants } \\
\cline { 2 - 3 } & $\mathrm{m}$ & $\mathrm{SD}$ \\
\hline Age & 31.80 & 10.36 \\
\hline The at onset of OCD & 20.35 & 6.99 \\
\hline Educational level (year) & 12.55 & 3.78 \\
\hline The number of comorbid Axis I disorders & 0.52 & 0.65 \\
\hline BAl & 22.07 & 14.85 \\
\hline YBOCS Total & 24.63 & 5.86 \\
Obsession & 12.72 & 3.29 \\
Compulsion & 11.90 & 3.26 \\
\hline CTQ-SF Total & 39.94 & 14.72 \\
Abuse & 22.10 & 9.47 \\
Neglect & 17.88 & 6.72 \\
\hline SPO Total & 32.13 & 15.74 \\
Cognitive-perceptual & 12.92 & 7.16 \\
Interpersonal & 13.15 & 6.52 \\
Disorganized & 6.05 & 4.49 \\
\hline & $\mathrm{n}$ & $\%$ \\
\hline Gender & & \\
Female & 78 & 67.8 \\
Male & 37 & 32.2 \\
\hline Marital status & & \\
Single & 54 & 47.0 \\
Married & 54 & 47.0 \\
Separated/divorced & 7 & 6.1 \\
\hline Comorbid Axis I Disorders & & \\
Present & 49 & 42.6 \\
\hline
\end{tabular}

OCD: Obsessive-Compulsive Disorder; BAl: Beck Anxiety Inventory; YBOCS: Yale-Brown ObsessiveCompulsive Scale; CTQ-SF: Childhood Trauma Questionaire Short Form; SPQ: Schizotypal Personality Questionnaire.

Table 2. Pearson correlations between $S P 0$ scores and clinical variables

\begin{tabular}{|l|c|c|c|c|c|c|}
\hline & $\begin{array}{c}\text { CTQ-SF } \\
\text { Abuse }\end{array}$ & $\begin{array}{c}\text { CTQ-SF } \\
\text { Neglect }\end{array}$ & $\begin{array}{c}\text { Duration } \\
\text { of OCD }\end{array}$ & $\begin{array}{c}\text { The } \\
\text { number } \\
\text { of Axis } \\
\text { I Dis }\end{array}$ & BAI & YBOCS \\
\hline SPO Cognitive-perceptual & $0.36^{* * *}$ & $0.25^{* *}$ & 0.01 & 0.06 & $0.47^{* * *}$ & $0.19^{*}$ \\
Interpersonal & $0.23^{* *}$ & $0.35^{* * *}$ & 0.07 & 0.18 & $0.49^{* * *}$ & 0.11 \\
Disorganized & $0.47^{* * *}$ & $0.34^{* * *}$ & 0.03 & 0.13 & $0.56^{* * *}$ & $0.32^{* *}$ \\
\hline
\end{tabular}

" $p<0.05 .{ }^{* *} p<0.005 .{ }^{\cdots *} p<0.0001$.

95\% CI [0.006-0.180], $\beta=0.232, t=2.115, p=0.03$ ) (Table 3). We suggested that childhood trauma mediated the schizotypal traits in the relation of current OCD severity independent from anxiety severity (Figure 1).

In examining the mediating effects of childhood neglect on the relationship between schizotypal traits and OCD severity, the linear regression analyses showed that total SPQ scores predicted the childhood neglect $(B=0.156,95 \%$ CI [0.080-0.232], $\beta=0.362$, $t=4.070, p<0.0001)$. The hierarchical regression revealed that after including childhood neglect, and BAI scores, direct effect of schizotypal traits on OCD severity disappeared $(B=0.095,95 \% \mathrm{CI}$ $[-0.088-0.278], \beta=0.087-0.110, t=0.513, p=0.60)$. Neither the mediator or independent variables were associated with the OCD severity. Therefore, we suggested that childhood neglect was not multivariately related to current OCD severity, and did not mediate the relationship between schizotypal traits and total YBOCS scores.

\section{Discussion}

Research examining the factors which are supposed to contribute the relationship between schizotypy and OCD symptoms is limited. Dysfunctional and maladaptive beliefs are supposed to be causal in
Table 3. Examining mediator effects using multiple regression

\begin{tabular}{|c|c|c|c|c|c|}
\hline $\begin{array}{l}\text { Testing steps in } \\
\text { mediation model }\end{array}$ & $\beta$ & S.E & B (95\% Cl) & $t$ & $p$ \\
\hline $\begin{array}{l}\text { Step } 1 \text { (Path a) } \\
\text { Outcome: } \\
\text { Childhood abuse } \\
\text { Predictor: } \\
\text { SPO } \\
\text { Step 2: (Path c) } \\
\text { Outcome: } \\
\text { YBOCS } \\
\text { Predictor: } \\
\text { SPO } \\
\text { Step } 3 \text { (Path b and c') } \\
\text { Outcome: } \\
\text { YBOCS } \\
\text { Mediator: } \\
\text { Childhood abuse } \\
\text { Predictors: } \\
\text { SPO } \\
\text { BAI }\end{array}$ & $\begin{array}{l}0.253 \\
0.062 \\
0.107\end{array}$ & $\begin{array}{l}0.067 \\
0.044 \\
0.048\end{array}$ & $\begin{array}{l}0.156(0.024-0.289) \\
0.062(-0.063-0.110) \\
0.107(-0.053-0.138)\end{array}$ & $\begin{array}{l}2.348 \\
0.538 \\
0.883\end{array}$ & $\begin{array}{l}0.02 \\
0.59 \\
0.13\end{array}$ \\
\hline $\begin{array}{l}\text { Step 1 (Path a) } \\
\text { Outcome: } \\
\text { Childhood neglect } \\
\text { Predictor: } \\
\text { SPO } \\
\text { Step 2: (Path c) } \\
\text { Outcome: } \\
\text { YBOCS } \\
\text { Predictor: } \\
\text { SPO } \\
\text { Step 3 (Path b and c') } \\
\text { Outcome: } \\
\text { YBOCS } \\
\text { Mediator: } \\
\text { Childhood neglect } \\
\text { Predictors: } \\
\text { SPO } \\
\text { BAI }\end{array}$ & $\begin{array}{l}0.106 \\
0.087 \\
0.176\end{array}$ & $\begin{array}{l}0.092 \\
0.045 \\
0.047\end{array}$ & $\begin{array}{l}0.033(-0.055-0.122) \\
0.095(-0.088-0.278) \\
0.070(-0.024-0.164)\end{array}$ & $\begin{array}{l}1.026 \\
0.745 \\
1.480\end{array}$ & $\begin{array}{l}0.30 \\
0.45 \\
0.14\end{array}$ \\
\hline
\end{tabular}

$\beta=0.224^{*}$

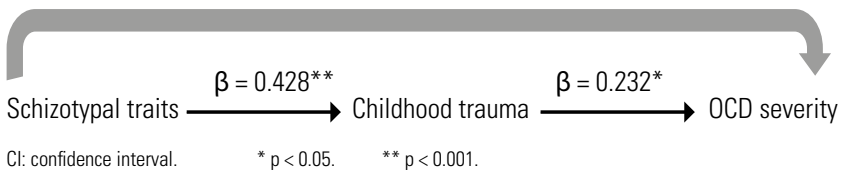

Figure 1. Statistical mediation model.

the development of a greater prevalance of OCD symptoms ${ }^{40}$. Lee et al. ${ }^{4}$ suggested that the magical thinking characteristics of schizotypy may increase the risk for OCD through the increased likelihood of TAF. According to the authors, TAF is associated with a set of cognitive biases that involve faulty causal relationships between one's own thoughts and external reality. In the present study, we investigated whether childhood abuse and/or neglect would mediate the relationship between schizotypy traits and OCD. First of all, we explored the relationship of schizotypal traits with several variables including the duration and severity of OCD, anxiety levels, childhood abuse and neglect. In consistent with some previous studies $4-6,8,12,15$, our results demonstrated that positive and disorganized schizotypal traits were signicifantly related to the current OCD severity. We have also found that current anxiety scores may interact between schizotypal symptoms and the current OCD severity.

Childhood trauma can contribute to the development of bizarre and unusual perceptions and beliefs ${ }^{14,19}$, and cognitive disorganisation ${ }^{41}$. In line with previous findings ${ }^{18,19,21,42}$, our findings indicated that there was an association between two types of childhood trauma (abuse 
and neglect) and increased positive, negative, and disorganized schizotypal traits. Therefore, these results are not in line with previous hypothesis which proposed that negative/disorganized schizotypal symptoms are more associated with alterations in early brain development, whereas positive symptoms are influenced more by environmental risk factors such as childhood trauma ${ }^{43,44}$. There is some evidence of a differential effect of trauma on schizotypy, with especially strong predictors being emotional abuse ${ }^{28}$ and neglect ${ }^{18}$. In fact, Johnson et al. ${ }^{21}$, found that childhood verbal abuse was associated with increased levels of schizotypal symptoms even after taking into account physical abuse, sexual abuse, and neglect. A previous study found that the association of emotional abuse with schizotypy remained significant even after adjusting for different types of childhood trauma ${ }^{45}$. Emotional abuse alone also predicted ideas of reference, excessive social anxiety, a lack of close friends, unusual perceptual experiences and eccentric behaviour or appearance 28 . Another study reported that physical and sexual abuse were associated with higher levels of paranoia/suspiciousness and unusual perceptual experiences ${ }^{46}$. Our results seemed to be inconsistent with some of the previous studies which identified that neglect was associated with positive and negative schizotypy whereas childhood emotional and physical abuse were only associated with the positive schizotypy dimension ${ }^{47}$. In a similar study, the subjects who reported emotional abuse did not show higher scores within any of three measures of schizotypy ${ }^{46}$.

Taking into account the strong correlations between two types of childhood trauma and three schiotypal dimensions, we supposed that childhood abuse and/or neglect may contribute to the influence of schizotypal traits on OCD. The mediation analysis revealed that childhood abuse mediated the relationship between schizotypal traits and OCD even after controlling for current anxiety scores. Similar to our results, a previous study ${ }^{29}$ demonstrated that childhood trauma, particularly emotional abuse had significant association with OCS independent from comorbid anxiety. The authors also suggested that there was an indirect relationship between emotional abuse and OCS mediated through the personality traits of conscientiousness. We found that although childhood neglect was significantly correlated with all types of schizotypy, it did not mediate the relationship between schizotypal traits and OCD. Furthermore, we suggested that sychizotypal traits were not associated with OCD severity when childhood neglect and current anxiety were controlled. Some previous research reported that childhood neglect appeared to be central in the development of schizotypy ${ }^{21,48}$. Our findings may suggest that although childhood neglect seemed to be related with schizotypal symptoms, it did not have a mediator role in further establishing of a relationship between OCD and schizotypal traits.

\section{Conclusions}

We believe that our study provides a substantial support to the primary hypothesis that childhood abuse experiences may mediate the relationship of schizotypal traits with OCD independent from higher levels of anxiety. The present findings may contribute to the literature by exploring the differential effects of specific trauma types in terms of mediators leading to schizotypal symptoms. Given that childhood emotional abuse may play a particularly important role in the development of psychopathology, longitudinal research examining the potential link between childhood emotional abuse, schizotypal traits and OCD is needed.

\section{Limitations}

The most obvious limitation in this research was that the number of participants was relatively small to adequately address the research questions or to possibly generalize beyond the context of this study. The use of self-report scales may have led to over-reporting of some symptoms and psychopathology. Also, the self-report instruments about childhood adverse experiences may suffer from the bias of memory and the bias of attributing meaning to the events lived by the respondent. We did not assess the duration and frequency of traumatic experiences, or the age when trauma first occurred. The role of gender, and educational level in moderating the relationship between study variables were not measured, since these variables were categorical or not normally distributed. Additionally, the neglect of the content of lifetime obsessions and compulsions, and the current diagnosis of depression in analyses is another limitation of this study. Morever, the data on comorbid diagnoses may not be sufficient, since they were collected in an interview, and not be checked in medical records.

\section{Conflict of interests}

The authors declare no conflict of interest.

\section{Funding}

This research did not receive any grant from any sources.

\section{Acknowledgments}

The authors thank the staff of psychiatry department for their assistance during the study.

\section{References}

1. Ruscio AM, Stein DJ, Chiu WT, Kessler RC. The epidemiology of obsessive-compulsive disorder in the National Comorbidity Survey Replication. Mol Psychiatry. 2010;15(1):53-63.

2. Sobin C, Blundell ML, Weiller F, Gavigan C, Haiman C, Karayiorgou M. Evidence of a schizotypy subtype in OCD. J Psychiatr Res. 2000;34(1): 15-24.

3. Brakoulias V, Starcevic V, Berle D, Milicevic D, Hannan A, Viswasam K, et al. The clinical characteristics of obsessive compulsive disorder associated with high levels of schizotypy. Aust N Z J Psychiatry. 2014;48(9):852-60.

4. Lee HJ, Cougle JR, Telch MJ. Thought-action fusion and its relationship to schizotypy and OCD symptoms. Behav Res Ther. 2005;43(1):29-41.

5. Chmielewski M, Watson D. The heterogeneous structure of schizotypal personality disorder: item-level factors of the Schizotypal Personality Questionnaire and their associations with obsessive-compulsive disorder symptoms, dissociative tendencies, and normal personality. J Abnorm Psychol. 2008;117(2):364-76.

6. Roth RM, Baribeau J. The relationship between schizotypal and obsessive-compulsive features in university students. Pers Indiv Differ. 2000;29(6):1083-93.

7. Dinn WM, Harris CL, Aycicegi A, Greene P, Andover MS. Positive and negative schizotypy in a student sample: neurocognitive and clinical correlates. Schizophr Res. 2002;56(1-2):171-85.

8. Suhr JA, Spitznagel MB, Gunstad J. An obsessive-compulsive subtype of schizotypy: evidence from a nonclinical sample. J Nerv Ment Dis. 2006;194(11):884-6.

9. Rossi A, Daneluzzo E. Schizotypal dimensions in normals and schizophrenic patients: a comparison with other clinical samples. Schizophr Res. 2002;1(54):67-75.

10. Vollema MG, Sistskoorn MM, Appels MC, Kahn RS. Does the Schizotypal Personality Questionnnaire reflect the biological-genetic vulnerability to schizophrenia? Schizoph Res. 2002;1(54):39-45.

11. Raine A. The SPQ: a scale for the assessment of schizotypal personality based on DSM III-R criteria. Schizophr Bull. 1991;17(4):555-64.

12. Einstein DA, Menzies RG. Role of magical thinking in obsessivecompulsive symptomsin an und ergraduate sample. Depress Anxiety. 2004;19(3):174-9.

13. Huang LC, Hwang TJ, Huang GH. Outcome of severe obsessive-compulsive disorder with schizotypal features: a pilot study. J Formos Med Assoc. 2011;110(2):85-92.

14. Tallis F, Shafran R. Schizotypal personality and obsessive compulsive disorder. Clin Psychol Psychoter. 1997;4:172-8.

15. Yamamoto H, Tsuchida H, Nakamae T, Nishida S, Sakai Y, Fujimori A, et al. Relationship between severity of obsessive-compulsive symptoms and schizotypy in obsessive-compulsive disorder. Neuropsychiatr Dis Treat. 2012;8:579-83. 
16. Moritz S, Fricke S, Jacobsen D, Kloss M, Wein C, Rufer M, et al. Positive schizotypal symptoms predict outcome in obsessive-compulsive disorder. Behav Res Ther. 2004;42(2):217-27.

17. Berenz EC, Amstadter AB, Aggen SH, Knudsen GP, ReichbornKjennerud T, Gardner CO, et al. Childhood trauma and personality disorder criterion counts: a co-twin control analysis. J Abnor Psychol. 2013;122(4):1070-6.

18. Berenbaum H, Valera EM, Kerns JG. Psychological trauma and schizotypal symptoms. Schizophr Bull. 2003;29(1):143-52.

19. Johnson JG, Cohen P, Smailes EM, Skodol AE, Brown J, Oldham JM. Childhood verbal abuse and risk for personality disorders during adolescence and early adulthood. Compr Psychiatry. 2001;42(1):16-23.

20. Cambell ML, Morrison AP. The relationship between bullying, psychoticlike experiences and appraisals in 14-16 year olds. Behav Res Ther. 2007;45(7):1579-91.

21. Johnson JG, Smailes EM, Cohen P, Brown J, Bernstein DP. Associations between four types of childhood neglect and personality disorder symptoms during adolescence and early adulthood: findings of a communitybased longitudinal study. J Pers Disord. 2000;14(2):171-87.

22. Raine A, Fung AL, Lam BY. Peer victimization partially mediates the schizotypy-aggression relationship in children and adolescents. Schizophr Bull. 2011;37(5):937-45.

23. Irwin HJ. The relationship between dissociative tendencies and schizotypy: an artifact of childhood trauma? J Clin Psychol. 2001;57(3):331-42.

24. Cannon TD, Mednick SA, Parnas J, Schulsinger F, Praestholm J, Vestergaard A. Developmental brain abnormalities in the offspring of schizophrenic mothers: II. Structural brain characteristics of schizophrenia and schizotypal personality disorder. Arch Gen Psychiatry. 1994;51(12):955-62.

25. Velikonja T, Fisher HL, Mason O, Johnson S. Childhood trauma and schizotypy: a systematic literature review. Psychol Med. 2015;45: 947-63.

26. McCabe KL, Maloney EA, Stain HJ, Loughland CM, Carr VJ. Relationship between childhood adversity and clinical and cognitive features in schizophrenia. J Psychiatr Res. 2012;46(5):600-7.

27. Ruby E, Polito S, McMahon K, Gorovitz M, Corcoran C, Malaspina D. Pathways associating childhood trauma to the neurobiology of schizophrenia. Front Psychol Behav Sci. 2014;3(1):1-17.

28. Powers AD, Thomas KM, Ressler KJ, Bradley B. The differential effects of child abuse and posttraumatic stress disorder on schizotypal personality disorder. Compr Psychiatry. 2011;52(4):438-45.

29. Mathews CA, Kaur N, Stein MB. Childhood trauma and obsessivecompulsive symptoms. Depress Anxiety. 2008;25(9):742-51.

30. Samuels J, Nestadt G, Bienvenu OJ, Costa PT Jr, Riddle MA, Liang KY, et al. Personality disorders and normal personality dimensions in obsessivecompulsive disorder. Br J Psychiatry. 2000;177:457-62.

31. First M, Spitzer R, Gibbon M, Williams J. Structured clinical interview for DSM-IV clinical version (SCID-I/CV). Washington DC: American Psychiatric Press; 1997.

32. Goodman WK, Price LH, Rasmussen SA, Mazure C, Fleischmann RL, Hill CL, et al The Yale-Brown Obsessive Compulsive Scale. I. Development, use, and reliability. Arch Gen Psychiatry. 1989;46(11):1006-11.
33. Tek C, Uluğ B, Rezaki BG, Tanriverdi N, Mercan S, Demir B, et al. YaleBrown Obsessive Compulsive Scale and US National Institute of Mental Health Global Obsessive Compulsive Scale in Turkish: reliability and validity. Acta Psychiatr Scand. 1995;91(6):410-3.

34. Rosario-Campos MC, Leckman JF, Mercadante MT, Shavitt RG, Hounie AG, Mercadante MT. Adults with early-onset obsessive-compulsive disorder. Am J Psychiatry. 2001;158(11):1899-903.

35. Bernstein DP, Stein JA, Newcomb MD, Walker E, Pogge D, Ahluvalia $\mathrm{T}$, et al. Development and validation of a brief screening version of the Childhood Trauma Questionnaire. Child Abuse Negl. 2003;27(2):169-90.

36. Sar V, Ozturk E, Ikikardes E. Validity and reliability of the Turkish version of Childhood Trauma Questionnnaire. Turkish Clin J Med Sci. 2012;32(4):1054-63.

37. Şener A, Bora E, Tekin I, Özaşkinli S. The reliability and validity of schizotypal personality questionnaire (SPQ) in Turkish students. Bull Clin Psychopharmacol. 2006;16(2):84-92.

38. Beck AT, Epstein N, Brown G, Steer RA. An inventory for measuring clinical anxiety: Psychometric properties. J Consult Clin Psychol. 1988;56(6):893-7.

39. Baron RM, Kenny DA. The moderator-mediator variable distinction in social psychological research: Conceptual, strategic, and statistical considerations. J Pers Soc Psychol. 1986;51(6):1173-82.

40. Bouchard C, Rheaume J, Ladouceur. Responsibility and perfectionism in OCD: an experimental study. Behav Res Ther. 1999;37(3):239-48.

41. Cavedo LC, Parker G. Parental bonding instrument. Exploring for links between scores and obsessionality. Soc Psychiatry Psychiatr Epidemiol. 1994;29(2):78-82.

42. Dominguez MD, Saka MC, Lieb R, Wittchen HU, van Os J. Early expression of negative/disorganized symptoms predicting psychotic experiences and subsequent clinical psychosis: a 10-year study. Am J Psychiatry. 2010;167(9):1075-82.

43. Heckers S, Goff D, Schacter DL, Savage CR, Fischman AJ, Alpert NM et al. Functional imaging of memory retrieval in deficit vs nondeficit schizophrenia. Arch Gen Psychiatry. 1999;56(12):1127-23.

44. Rowland LM, Spieker EA, Francis A, Barker PB, Carpenter WT, Buchanan RW. White matter alterations in deficit schizophrenia. Neuropsychopharmacology 2009;34(6):1514-22.

45. Afifi TO, McMillan KA, Asmundson GJ, Pietrzak RH, Sareen J. An examination of the relation between conduct disorder, childhood and adulthood traumatic events, and posttraumatic stress disorder in a natioanally representative sample. J Psychiatr Res. 2011;45(12):1564-72.

46. Steel C, Marzillier S, Fearon P, Ruddle A. Childhood abuse and schizotypal personality. Soc Psychiatry Psychiatr Epidemiol. 2009;44(11):917-23.

47. Heins M, Simons C, Lataster T, Pfeifer S, Versmissen D, Lardinois M, et al. Childhood trauma and psychosis: a case-control and case-sibling comparison different levels of genetic liability, psychopathology, and type of trauma. Am J Psychiatry. 2011;168(12):1286-94.

48. Wong KK, Raine A, Venables P. The effect of being left home alone at age 3 years on schizotypy and antisocial behavior at ages 17 and 23 years. J Psychiatry Res. 2018;105:103-12. 